\title{
Educational program promoting regular physical exercise improves functional capacity and daily living physical activity in subjects with knee osteoarthritis
}

José Messias Rodrigues da Silva 1,2,3, Márcia Uchoa de Rezende², Tânia Carvalho Spada ${ }^{2,3}$, Lucila da Silva Francisco ${ }^{3}$, Fabiane Elize Sabine de Farias ${ }^{2}$, Cleidnéia Aparecida Clemente da Silva ${ }^{2}$, Claudia Helena de Azevedo Cernigoy², Júlia Maria D'Andréa Greve ${ }^{2}$ and Emmanuel Gomes Ciolac ${ }^{1 *}$

\begin{abstract}
Background: Physical exercise and educational programs promote several benefits for patients with knee osteoarthritis $(\mathrm{OA})$. However, little is known about the effects of educational programs promoting the regular practice of physical exercise. The purpose of the present study was to assess the effect of an interdisciplinary educational program, emphasizing the recommendation for regular practice of physical exercise, on functional capacity and daily living physical activity in individuals with knee $O A$.

Methods: Two hundred and thirty-nine individuals (50 men) with an established diagnosis of knee OA (degree I to IV in the Kelgreen and Lawrence scale) were randomly allocated into a multidisciplinary educational program (EDU; $n=$ 112 ) or control group (CON; $n=127)$. Functional capacity (sit and reach, 6 -min walking test (6MWT), timed up and down stairs test, timed up and go test (TUGT), and five times sit-to-stand test (FTSST)) and daily living physical activity (IPAQ, short version) were measured before, during (6 months) and after 12 months of follow-up.

Results: Body mass index reduced significantly $(P<0.05)$ after 6 months, and remained reduced after 12-month of follow-up in EDU, but not in CON. EDU group improved $(P<0.05)$ timed up and down stairs (19\%), TUGT (32.5\%) and FTSST (30\%) performance after 6 months of follow-up, which remained improved after 12 months of follow-up. Functional capacity did not change in CON, excepted for the timed up and down stairs performance that increased after 6 months $(12 \%, P<0.05)$, but returned to levels similar to baseline after 12 months of follow-up. There was also an increase $(P<0.05)$ in the prevalence of active and very active individuals, as well as a reduction $(P<0.05)$ in the prevalence of sedentary individuals in EDU group during follow-up. There were no significant changes on sit and reach and 6MWT performance during follow-up in both groups.
\end{abstract}

Conclusions: The results suggest that an educational program emphasizing the recommendation for regular practice of physical exercise may be an effective tool for improving functional capacity and daily physical activity in individuals with knee OA.

Trial registration: NCT 02335034, December 22, 2014.

Keywords: Daily living physical activity, Educational program, Physical fitness, Functional capacity, Physical exercise, Osteoarthritis

\footnotetext{
* Correspondence: ciolac@fc.unesp.br

${ }^{1}$ São Paulo State University (UNESP), School of Sciences, Campus Bauru,

Physical Education Department, Exercise and Chronic Disease Research

Laboratory, Bauru, Brazil

Full list of author information is available at the end of the article
} 


\section{Background}

The population aging is an unprecedented worldwide phenomenon that affects both developed and developing countries $[1,2]$. The high prevalence of chronic disease that accompany the population aging, in association with the age-related deterioration that occurs in almost all physiological systems, results in reduced independence and quality of life in elderly individuals [2, 3]. Osteoarthritis (OA) of the knee is one of the most prevalent agerelated chronic diseases, whereas one in four people over 55 years of age has persistent knee pain [4].

Although there is no curative treatment, the optimal management of knee OA requires pharmacological and non-pharmacological modalities, which are focused on alleviating disease symptoms, maintaining or improving patients' functional independence and quality of life, and reducing disease progression to attempt to delay or avoid total knee arthroplasty [5]. The regular practice of physical exercise is an important non-pharmacological tool recommended for managing disease symptoms and improving functional capacity in patients with knee OA $[3,6,7]$.

It has been suggested that educational programs may also have positive effects in individuals with knee OA [8]. For example, a study by our group showed that educational programs improved pain, function and quality of life (both physical and mental) after 6 [9] and 12 month of follow-up [10]. Therefore, to change the habits may have important clinical implication for this population, and the regular practice of physical exercise appears to be a crucial habit that should be incorporated in the daily living $[3,7,9,10]$.

The purpose of the present study was to assess the effect of an interdisciplinary educational program, emphasizing the recommendation for regular practice of physical exercise, on functional capacity and daily living physical activity in individuals with knee OA. We hypothesized that the educational program emphasizing the regular practice of physical exercise would be superior than conventional medical treatment.

\section{Methods}

\section{Population and study design}

The present investigation was a longitudinal prospective study conducted in a single center in Brazil that assessed 300 middle-aged and older patients with an established diagnosis of bilateral (294 patients) or unilateral knee $\mathrm{OA}$ for at least 1 year (Kellgren/Lawrence scale grades of I-IV) [11]. All volunteers were recruited from the Osteometabolic Disease Group, Institute of Orthopedics and Traumatology, School of Medicine, University of São Paulo, and they were under drug therapy (diacerein) for the 6 months prior to inclusion. To meet the eligibility criteria, patients needed to have met the American
College of Rheumatology criteria for knee OA [12], to not have rheumatoid arthritis or any other rheumatologic disease other than $\mathrm{OA}$, to be under routine care for knee OA for at least the previous 6 months, to not have any neurological problems, and to be able to understand and provide informed consent. Patients with uncontrolled cardiovascular or metabolic diseases, who underwent surgery or who had lower limb injuries during the previous 6 months were also not included. Baseline characteristics of the volunteers included in the present study are presented in Table 1.

Following screening for inclusion criteria, the volunteers have their functional capacity and physical activity levels assessed before, and after 6 and 12 months of follow-up. Volunteers were then randomly allocated into an educational program (EDU; $n=150$ ) or control group (CON; $\mathrm{n}=150)$ (Fig. 1). The EDU group participated in an educational program by a multidisciplinary group (orthopedic surgeons, physical education professionals, nutritionists, physiotherapists, occupational therapists, psychologists and social workers), which emphasized the recommendation for regular practice of home-based exercise in addition to the conventional clinical treatment. The CON group received only the conventional clinical treatment. The functional capacity and physical activity levels assessment were performed by members of the physical education team that were blinded for volunteers' groups allocation.

The conventional treatment for knee OA included clinical follow-up by orthopedic surgeons; blood testing for metabolic syndrome (and referring for general practitioner clinical treatment as indicated), and calcium metabolism; X-rays, densitometry, and more

Table 1 Baseline characteristics of the volunteers

\begin{tabular}{lll}
\hline Variable & EDU & CON \\
\hline $\mathrm{N}$ & 150 & 150 \\
F/M & $121 / 29$ & $114 / 36$ \\
Age (years) & $68.2 \pm 9.6$ & $66.3 \pm 9.6$ \\
Body weight (kg) & $78.0 \pm 16.2$ & $80.0 \pm 15.1$ \\
Height (m) & $1.58 \pm 0.09$ & $1.57 \pm 0.08$ \\
BMI (kg/m ${ }^{2}$ ) & $31.3 \pm 5.9$ & $32.1 \pm 5.7$ \\
Bilateral osteoarthritis (N) & 144 & 150 \\
Unilateral osteoarthritis R/L (N) & $2 / 4$ & 0 \\
Kellgren and Lawrence scale & & $3(2)$ \\
Degree I (N (\%)) & $4(2.7)$ & $66(44)$ \\
Degree II (N (\%)) & $38(25.3)$ & $47(31.3)$ \\
Degree III (N (\%)) & $65(43.3)$ & $34(22.7)$ \\
\hline Degree IV (N (\%)) & $43(28.7)$ &
\end{tabular}

$B M I$ Body Mass Index, $C O N$ control group, EDU educational program group, $F$ female, $L$ Left, $M$ male, $N$ number of patients, $R$ Right 


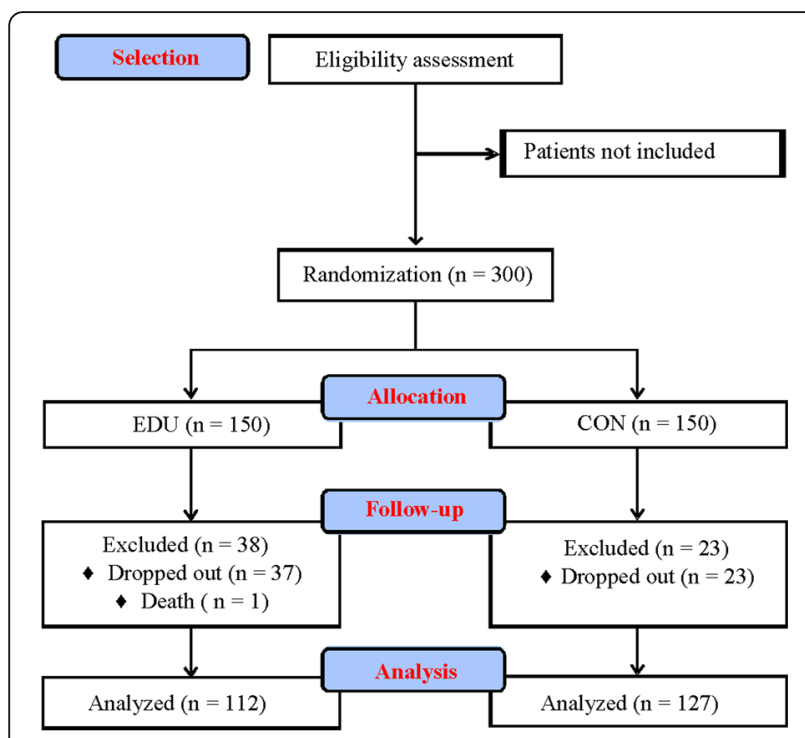

Fig. 1 Schematic representation of the study design

specific image exams (e.g. ultrasound and magnetic resonance imaging) according to symptoms. Diacerhein was prescribed for all volunteers. A muscle relaxant and magnesium were prescribed for volunteers who reported cramps. All volunteers were oriented to take paracetamol and codeine when presenting moderate to severe knee pain. Low doses of nonsteroidal anti-inflamatory drugs were used only occasionally for severe pain, and during short periods of time. Vitamin D3 and calcium supplements were prescribed according to blood levels and bone densitometry results. Alendronate was prescribed for volunteers with osteoporosis. When necessary, orthotics (i.e. valgus or varus insoles, canes, walkers, and custom-made hand orthotics) were prescribed according to the disease severity, which was assessed by 3 orthopedic surgeons using the Kellgren and Lawrence classification, as previously described [10]. Volunteers with impaired mobility and pain were also referred to physical therapy and acupuncture.

\section{Functional capacity and physical activity assessment}

All EDU and CON volunteers underwent functional capacity and physical activity levels assessment before and during 6 and 12 months of follow-up. Measures of functional capacity included the sit and reach, 6-min walking test (6MWT), timed up and down stairs test, timed up and go test (TUGT), and five times sit-to-stand test (FTSST), which were performed in a single day, following the sequence described below, and with a 3-min rest interval between them. The classic sit and reach test was used to assess the posterior thigh and lower back flexibility as previously described [13]. The 6MWT measured the distance covered while walking on a $15 \mathrm{~m}$ corridor without inclination. Volunteers were instructed to walk as fast as possible (without running) at a steady pace [14], and had their baseline (pre-test), peak (immediately after the end of the test) and recovery ( $2 \mathrm{~min}$ after the end of the test) heart rate measured with a digital frequency meter (Polar F1, Polar, Finland). The timed up and down stairs test measured the time taken to ascend and descend a flight of 15 steps $(15 \mathrm{~cm}$ high and $30 \mathrm{~cm}$ depth) as quickly as possible, starting from the standing position with their preferred leg, whereas it was allowed to use the handrail if necessary [15]. The FTSST measured the time taken to perform 5 repetitions of rising from a standard chair without armrest (seat height of $46 \mathrm{~cm}$ ) to a full upright position as quickly as possible and without assistance [16]. The TUGT measured the time to get up from a chair without armrest (seat height of $46 \mathrm{~cm}$ ) and without assistance, walk $3 \mathrm{~m}$ at normal speed, turn around, walking back and sitting down [17]. After the functional capacity assessment, the International Physical Activity Questionnaire (IPAQ) short version (validated in Brazilian population) was used to assess the daily physical activity level in all volunteers [18].

\section{Educational program}

In addition to the conventional medical treatment, EDU group underwent an educational program with the health professional multidisciplinary team in order to make volunteers aware of their illness $(\mathrm{OA})$ and their role on its treatment/management. The educational program occurred in a single day (Saturday, from 8 a.m. to 5 p.m.), and included 7 lectures of $30 \mathrm{~min}$ by each professional team, and 60-min workshops by the physical education, physical therapy and occupational therapy professionals, approaching the importance of their area in knee OA treatment/management.

The lectures occurred at morning. The orthopedic surgeon team introduced the anatomy of a joint and the pathophysiology of knee OA, its causes, irreversibility, and management. The physical education professionals lectured was about the health-related benefits of physical exercise and its role on knee OA management, the differences between physical activity and exercise, and the importance of improving physical fitness. The physical therapists also called attention for the role of performing physical exercise regularly, showed how to improve physical exercise to move from pain to a state of no pain, and talked about techniques to alleviate pain. The occupational therapists introduced the importance of protecting joints in daily activities by optimizing ergonomics and alternating different levels of energy expenditure. The nutritionist talked about the importance of a well-balanced diet (reduced quantity, colorful, whole grains, and low-calorie meals). The psychology team 
lectured about personality characteristics from childhood to adulthood, the difference between having a disease and being sick, the importance of their choices and not their conditions or feelings, and coping skills. The social work team showed where and how volunteers could and should include habits of regular leisure, sports and social gathering, and tasks. It is important to note that the role of changing habits was reinforced by each professional team, whereas the importance of practicing regular exercise was commented in all lectures.

The 3 workshops occurred at afternoon. The physical education workshop was about how to perform exercise (resistance and aerobic) at home, using low-cost alternative tools, as well as how to exercise at the appropriate exercise intensity. Volunteers were instructed to accumulate 30 to $60 \mathrm{~min} /$ day (bouts of at least $10 \mathrm{~min}$ ) of moderate-intensity aerobic exercise (11 to 13 at the 620 rating of perceived (RPE) scale) [19], for 5 days a week. Alternatively to the moderate-intensity aerobic exercise recommendation, if physical capacity and disease severity allowed, volunteers were instructed to accumulate 20 to $30 \mathrm{~min} /$ day (bouts of at least $10 \mathrm{~min}$ ) of vigorous-intensity aerobic exercise (14 to 16 at the 6-20 RPE scale) [19], for 3 days a week. Volunteers were instructed to perform the aerobic exercise modality they prefer (e.g.: walking, stationary cycling, dancing, swimming...). However, if weight bearing aerobic exercise was not tolerated (e.g.: there was a knee pain increase during or after exercise), they were instructed to perform stationary cycling or aquatic exercise. In addition to aerobic exercise recommendation, volunteers were instructed to perform 2 to 3 sets of 8 to 12 repetitions ( 1 to 2 min of interval between sets), in 10 resistance exercise (bench press, squat, seated row, knee extension, shoulder press, knee curl, triceps push-down, calf raise, biceps curl, and abdominal), for 3 times a week (nonconsecutive days). The volunteers were taught that they could perform the resistance exercises using weight-lifting machines, weight bearing, dumbbells, or some adapted material taught in the classes, (ankle weights, bars, elastic band, bottles with water or sand...), at an intensity between 14 and 17 at the 6-20 RPE scale) [19], using proper form and avoiding the Valsalva maneuver. The physical therapy team taught the volunteers how to adapt the exercise recommendation if they had knee pain and what they could do to alleviate knee pain at home, whereas the occupational therapy team taught how to protect the joints during both exercise and daily living activities.

The volunteers also received a printed material containing summaries of all lectures, and the exercises and practical recommendations of the 3 workshops, as well as a DVD with all the lectures and workshops. All volunteers were asked to watch the DVD and/or to read the booklet at least 3 times.

\section{Statistical analysis}

The Kolmogorov-Smirnov test was used to analyze data normality. Parametric variables were reported as mean \pm standard error, whereas non-parametric variables (physical activity levels) were reported as percentage of prevalence. Two-way ANOVA with repeated measures (group vs. time) was used to indicate inter- and intrainterventions differences in data presenting Gaussian distribution, and the Bonferroni's post hoc test was performed to identify significant differences indicated by ANOVA. The Chi-square test was used to analyze interand intra-interventions differences in physical activity levels. The statistical program SPSS ${ }^{\text {тм }} 17.0$ for Windows (SPSS Inc., Chicago, IL, EUA) was used to perform the statistical analysis.

\section{Results}

Two hundred and thirty nine volunteers completed the follow-up and were included in final analysis. The reasons for not inclusion in final analysis were no participation in the educational lectures and/or workshops (12 volunteers from EDU), no participation in all physical functional assessments during follow-up (25 volunteers from EDU and 23 volunteers from CON) and death (one volunteer from EDU) (Fig. 1). There were no significant differences in baseline characteristics between volunteers who completed the follow-up and those who did not (data not shown).

The two-way ANOVA indicated significant intra- and inter-intervention differences in body mass index (BMI) $(P<0.05)$. Post hoc analysis did not show significant BMI differences between group at baseline. However, BMI reduced after 6 months and remained lower after 12 months of follow-up $(P<0.05)$ only in EDU. With the reduction, BMI was significant lower $(P<0.05)$ in EDU than CON after 6 and 12 months of follow-up (Table 2).

There were no significant inter- or intra-intervention differences in 6MWT distance or HR response (Table 3). Although there was no significant intra-intervention difference, significant inter-intervention difference was found in sit and reach test $\left(F_{1,42}=4.837, P=0.033\right)$. Post hoc analysis showed that sit and reach levels were higher in EDU than CON throughout the follow-up (Table 4).

There were inter- $\left(F_{2.3}, 94.4=5.936, P=0.002\right)$ and intra-intervention differences $\left(F_{1,41}=6.006, P=0.02\right)$ in up and down stairs test. Post hoc analysis showed that time to up and down stairs reduced nearly $19 \%(P<$ $0.05)$ after 6 months, and remained reduced $(P<0.05)$ after 12 months of follow-up in EDU volunteers. Time to up and down stairs also reduced during 6 months of follow-up $(P<0.05)$ in CON volunteers; however, this reduction was lower than that observed in EDU (19\% vs. $12 \%, \mathrm{P}<0.05)$ and was not maintained after 12 months of follow-up (Table 4). 
Table 2 Body mass index before and during 6 and 12 months of follow-up

\begin{tabular}{llll}
\hline BMI & Before & 6 months & 12 months \\
\hline EDU $(N=112)$ & $31.1 \pm 0.5$ & $30.6 \pm 0.4^{*^{\dagger}}$ & $30.5 \pm 0.5^{*^{\dagger}}$ \\
CON $(N=127)$ & $32.1 \pm 5.7$ & $32.6 \pm 6.3$ & $32.6 \pm 6.2$ \\
\hline
\end{tabular}

$B M I$ Body mass index $\left(\mathrm{kg} / \mathrm{m}^{2}\right)$, CON control group, EDU educational program group. Asterisk denotes significant difference from before follow-up in the same group $\left({ }^{*}: P<0.05\right)$. Dagger denotes significant difference from control group during the same period $\left({ }^{\dagger}: P<0.05\right)$

There was significant intra- and inter-intervention interaction in TUGT $\left(F_{2.7}, 130.2=6.568, P<0.001\right)$. Post hoc analysis showed that TUGT improved $(P<0.01)$ after 6 months (nearly 30\%) and remained improved after 12 months (nearly 37\%) of follow-up only in EDU, which resulted in a TUGT level significant lower $(P<0.05)$ in EDU than CON after 12 months of follow-up (Table 4).

There were significant intra- $\left(F_{3}, 153=8.829, P<0.001\right)$ and inter-intervention $\left(F_{1,51}=8.956, P=0.004\right)$ difference in FTSST. Post hoc analysis showed significant FTSST reduction $(P<0.001)$ after 6 months (nearly $32.5 \%)$ only in EDU volunteers, which were maintained after 12 months of follow-up. With this reduction, FTSST levels were significant lower $(P<0.01)$ in EDU than CON both after 6 and 12 months of follow-up (Table 4).

Daily physical activity levels are presented in Table 5. Lower prevalence $(P<0.05)$ of active and very active volunteers, as well as higher prevalence $(P<0.05)$ of sedentary volunteers were found in EDU than CON at before follow-up. However, the prevalence of active and very active volunteers increased $(P<0.05)$ after 6 months, and remained increased after 12 months of follow-up in EDU. EDU also reduced $(P<0.05)$ prevalence of sedentary volunteers after 6 months, which was maintained after 12 months of follow-up. A significant increase $(P<0.05)$ in the prevalence of very active volunteers after 6 months of follow-up, which was maintained after 12 months of follow-up, was the only change found in $\mathrm{CON}$.

Table 3 Variables of 6-min walking test before and after 6 and 12 months of follow-up

\begin{tabular}{lllll}
\hline & Variable & Pre & 6 months & 12 months \\
\hline EDU (N =112) & Distance $(\mathrm{m})$ & $368.6 \pm 9.15$ & $375.9 \pm 9.8$ & $385.6 \pm 9.3$ \\
& HR resting $(\mathrm{bpm})$ & $76 \pm 1.9$ & $75.7 \pm 2.5$ & $77.8 \pm 2.7$ \\
& HR peak (bpm) & $97.2 \pm 2.8$ & $97.3 \pm 3.5$ & $99.2 \pm 3.4$ \\
& HR & $76.6 \pm 2.3$ & $75.9 \pm 2.6$ & $76.9 \pm 2.7$ \\
& recovery (bpm) & & & \\
CON (N=127) & Distance $(\mathrm{m})$ & $357.5 \pm 7.1$ & $379.1 \pm 7.6$ & $366.1 \pm 8.8$ \\
& HR resting (bpm) & $75.0 \pm 1.1$ & $74.7 \pm 1.2$ & $74.9 \pm 1.4$ \\
& HR peak (bpm) & $103.6 \pm 1.7$ & $99.3 \pm 1.7$ & $98.3 \pm 1.7$ \\
& HR & $83.7 \pm 1.0$ & $77.0 \pm 1.1$ & $75.2 \pm 1.3$ \\
& recovery (bpm) & & & \\
\hline
\end{tabular}

CON control group, EDU educational program group, HR Heart rate

\section{Discussion}

The primary finding of the present study was that EDU was superior to $\mathrm{CON}$ for improving several functional performance, including up and down stairs, TUGT and FTSST, in individuals with knee OA. According to our knowledge, the present study is pioneer in assessing the effect of an interdisciplinary educational program, emphasizing the recommendation for regular practice of physical exercise, on functional capacity and daily living physical activity in individuals with knee OA.

The effect of educational programs in individuals with OA has been previously investigated [20,21]. Studies investigating the effects of educational programs associated with medical consultation have shown improvements in symptoms and in treatment compliance, which may have positive impact on quality of life and functional capacity in individuals with knee OA [20-22]. However, functional capacity has been primarily assessed through self-administered questionnaires [20, 23]. More recently, the TUGT and FTSST has shown to improve after educational programs in individuals with knee OA $[24,25]$. The present study was pioneer in investigating the effect of an educational program on functional capacity measured through different tests that represent the ability to perform different daily activities. The improvement in TUGT, FTSST and up and down stairs performance observed in EDU, associated with the no changes found in CON, suggests that an educational program emphasizing the recommendation for regular practice of physical exercise can be effective for improving functional capacity in individuals with knee OA.

Although little is known about the effect of educational programs on functional capacity, it is known that physical exercise programs, specifically resistance training, promote improvement on functional capacity in individuals with knee OA [3, 7, 26]. For example, 13 weeks of a twice-weekly whole body resistance training program resulted in improvements on FTSST and stair climbing performance in individuals with total knee arthroplasty and OA in the contralateral knee [7], which were similar to those observed in the present study. The substantial improvements in FTSST (nearly 32.5\%), TUGT (nearly 30\%) and up and down stairs (19\%) performance of EDU volunteers suggest that the educational program emphasizing the recommendation for regular practice of physical exercise used in the present study may be an alternative to conventional resistance exercise programs for improving functional capacity in individuals with knee OA.

It is possible that the substantial functional capacity improvements promoted by the educational program used in the present study may be due to its emphasis on the recommendation for regular practice of physical exercise. It is important to note that most 
Table 4 Functional capacity before and during follow-up

\begin{tabular}{lllll}
\hline & Variable & Before & 6 months & 12 months \\
\hline EDU $(N=112)$ & Sit and reach $(\mathrm{cm})$ & $17.5 \pm 0.8^{\dagger}$ & $17.3 \pm 0.9^{\dagger}$ & $17.9 \pm 0.9^{\dagger}$ \\
& Up and down stairs (sec) & $30.3 \pm 2.3$ & $24.3 \pm 2.4^{*^{\dagger}}$ & $24.4 \pm 1.6^{*^{\dagger}}$ \\
& TUGT (sec) & $16.4 \pm 0.7$ & $11.5 \pm 0.5^{* *}$ & $10.4 \pm 0.7^{* *^{\dagger}}$ \\
& FTSST (sec) & $25.3 \pm 1.3$ & $17.1 \pm 0.9^{* * *^{+\dagger}}$ & $18.4 \pm 1.1^{* * *^{+\dagger}}$ \\
CON (N=127) & Sit and reach (cm) & $12.0 \pm 0.7$ & $11.9 \pm 0.8$ & $13.2 \pm 1.0$ \\
& Up and down stairs (sec) & $34.5 \pm 1.2$ & $30.2 \pm 1.3^{*}$ & $32.2 \pm 1.9$ \\
& TUGT (sec) & $12.4 \pm 0.4$ & $12.5 \pm 0.4$ & $12.6 \pm 0.5$ \\
& FTSST (sec) & $27.6 \pm 1.3$ & $24.9 \pm 1.0$ & $22.8 \pm 1.4$ \\
\hline
\end{tabular}

CON control group, EDU educational program group, FTSST five times sit-to-stand test, TUGT timed up and go test. Asterisk denotes significant difference from before follow-up in the same group $\left({ }^{*}: P<0.05 ;{ }^{* *}: P<0.01 ;{ }^{* * *}: P<0.001\right)$. Dagger denotes significant difference from control group during the same period $\left(^{\dagger}: P\right.$ $\left.<0.05 ;{ }^{++}: P<0.01\right)$

studies analyzing the effect of educational programs in individuals with knee OA had only one or two health professionals providing the educational program [20-22, 27]. In the present study, the multidisciplinary educational program involved seven professional teams (orthopedic surgeons, physical education professionals, nutritionists, physiotherapists, occupational therapists, psychologists and social workers). The increase in the prevalence of active/ very active volunteers and the reduction in the prevalence of sedentary volunteers observed in EDU during the follow-up suggest that the recommendation for regular practice of physical exercise may have an important role in the functional capacity improvements found in the present study.

The educational program also resulted in BMI reduction after 6 months and its maintenance after 12 months of follow-up, whereas CON group showed no changes in this variable. It has been shown that longevity and obesity results in worsening of knee OA symptoms and severity $[27,28]$, and that weight

Table 5 Physical activity level before and during follow-up

\begin{tabular}{lllll}
\hline & Classification & Before & 6 months & 12 months \\
\hline EDU (N =112) & Very Active (\%) & $2.5^{\dagger}$ & $16^{*}$ & $18.5^{*}$ \\
& Active (\%) & $21^{\dagger}$ & $43^{*}$ & $42.5^{*}$ \\
& Irregularly active A (\%) & 28.5 & 19 & 15.5 \\
& Irregularly active B (\%) & 26 & 13 & 14.5 \\
& Sedentary (\%) & $22^{\dagger}$ & $9^{*}$ & $9^{*}$ \\
CON (N = 127) & Very Active (\%) & 11.5 & $22^{*}$ & $25^{*}$ \\
& Active (\%) & 42 & 38.5 & 39 \\
& Irregularly active A (\%) & 16 & 15.5 & 18 \\
& Irregularly active B (\%) & 18 & 18 & 11.5 \\
& Sedentary (\%) & 12.5 & 6 & 6.5 \\
\hline
\end{tabular}

CON control group, EDU educational program group. Asterisk denotes significant difference from before follow-up in the same group $\left({ }^{*} P<0.05\right.$ ). Dagger denotes significant difference from control group during the same period $\left({ }^{\dagger}: P<0.05\right)$ loss may improve pain, quality of life and functional scores in this population [29]. Thus, it is reasonable to suggest that the BMI reduction observed in EDU, although of small magnitude, may have influenced the improvement in functional capacity of those volunteers. In addition, BMI reduction may have been beneficial not only because of the reduction in joint overload, but also because of a possible improvement in obesity-related metabolic alterations [29]. Adipose tissue is a multifunctional organ that, in addition to its function as an energy store, plays an important role in endocrine system by producing adipokines. Several adipokines may act on immune system cells, leading to local and systemic inflammation [30]. In diseases with acute or chronic inflammation (i.e., such as knee OA), adipokines are associated with the pathophysiology of pain syndromes [31]. In contrast, physical exercise-related reduction in body fat is associated with prophylaxis of $\mathrm{OA}$ and pain improvement [31]. In addition to the OA-related benefits, the BMI reduction observed in EDU during follow-up may also have benefits for other chronic diseases present in the studied population, such as diabetes and arterial hypertension [32].

Functional walking capacity was measured by 6MWT, which can also be used as an indicator of aerobic capacity. This submaximal test has been widely used due its safety, feasibility, low cost and good tolerance, which allows its application even in advanced age groups, mainly because of its self-regulated pace and possibility of pausing or interrupting the walking if necessary [14]. It is suggested that the distance walked during the 6MWT should be compared with reference values, whereas predictive equations have been developed since 1998 [33]. In Brazilian population, the mean distance walked by adults aged 20 to 80 years is $566 \pm 87 \mathrm{~m}$ and $538 \pm 95 \mathrm{~m}$ for men and women, respectively [33]. For individuals with musculoskeletal limitations, it is suggested the use of a quadratic prediction model, which predicts that the 
population studied should walk $303.51 \mathrm{~m}$ during the 6MWT [33]. The EDU and CON volunteers walked $368.6 \pm 9.15 \mathrm{~m}$ and $357.5 \pm 7.1 \mathrm{~m}$, respectively, during the $6 \mathrm{MWT}$ before follow-up. Thus, it is reasonable to suggest that volunteers initial aerobic capacity were above the predicted, which may be a reason why educational program was not effective for improving 6MWT performance. Supporting this hypothesis, a previous study assessing 6MWT performance in individuals with total knee arthroplasty and OA in the contralateral knee, that had a before follow-up 6MWT walking distance lower than the population in the present study (nearly $270 \mathrm{~m}$ ), found substantial improvement $(22.6 \%)$ in walking distance after 13 weeks of resistance training [7].

Although the sample size was large, the number of male volunteers was relatively small and may not represent the entire population of men with knee OA. Thus, future studies with greater prevalence of men are needed. The greater prevalence of sedentary individuals $(22 \%$ vs. $12.5 \%)$ and lower prevalence of active $(21 \%$ vs. $42 \%)$ and very active individuals $(2.5 \%$ vs. $11.5 \%)$ in EDU than CON at baseline is also a limitation of present study, because it may interfere in the between group difference during follow-up. However, the within group analysis suggest that the educational program was effective for reducing the prevalence of sedentary individuals, and for increasing the prevalence of active and very active individuals during follow-up.

Reduced levels of functional capacity is associated with increased levels of disability, daily living dependence, hospitalization and mortality [7, 34, 35]. In this context, the functional capacity improvements observed in EDU individuals, but not in CON, suggest that the educational program of the present study may have important implications for reducing the risk of disability, daily living dependence, hospitalization and mortality.

\section{Conclusions}

The results of the present study suggest that an educational program emphasizing the recommendation for regular practice of physical exercise was effective for improving functional capacity and daily physical activity in individuals with knee OA. However, the present educational program appears to be ineffective for improving aerobic capacity.

\section{Abbreviations \\ 6MWT: 6-min walk test; BMI: Body mass index; CON: Control group: EDU: Educational program group; FTSST: Five times sit-to-stand test; IPAQ: International Physical Activity Questionnaire; OA: Osteoarthritis; TUGT: Timed up and go test}

\section{Acknowledgements}

This work is part of José M. Rodrigues da Silva's Master of Sciences dissertation under the guidance of Dr. Emmanuel G. Ciolac. This study was only possible because of the efforts of secretaries Suellen Lima and Natalia Borges and support from TRB Pharma, which together with the Department of Orthopedics and Traumatology at the Hospital das Clinicas at FMUSP and Professor Olavo Pires de Camargo, made the PARQVE project and this prospective study possible. We also thank Fundação de Amparo à Pesquisa do Estado de São Paulo (FAPESP) and Comissão de Aperfeiçoamento de Pessoal de Nivel Superior (CAPES) for the constant support to our research in Brazil.

\section{Funding}

This research was supported by the orthopedics department and TRB PHARMA Brasil [no grant number].

\section{Availability of data and materials}

The datasets generated and analyzed during the current study are available from the corresponding author on reasonable request.

\section{Authors' contributions}

JMRS participated in the study design, data collection, analysis and manuscript preparation. MUR participated in the study design, data collection and manuscript preparation. TCS and LSF participated in the data collection and manuscript preparation. FESF, CACS and CHAC participated in the data collection and study design. JMDG participated in the study design and manuscript preparation. EGC participated in the study design, data analysis and manuscript preparation. All authors have read and approved the manuscript.

\section{Ethics approval and consent to participate}

The present study was approved by the Ethics Committee for Analysis of Research Projects of the Hospital das Clínicas da Faculdade de Medicina da Universidade de São Paulo (\# CAPPesq 12,671). All volunteers read a detailed description of the protocol and provided their written informed consent.

\section{Consent for publication}

Not applicable

\section{Competing interests}

The authors declare that they have no competing interests.

\section{Publisher's Note}

Springer Nature remains neutral with regard to jurisdictional claims in published maps and institutional affiliations.

\section{Author details}

${ }^{1}$ São Paulo State University (UNESP), School of Sciences, Campus Bauru, Physical Education Department, Exercise and Chronic Disease Research Laboratory, Bauru, Brazil. ${ }^{2}$ University of São Paulo, School of Medicine, Department of Orthopedics and Traumatology, Sao Paulo, Brazil. ${ }^{3}$ University of Guarulhos (UNG), Guarulhos, SP, Brazil.

Received: 20 July 2017 Accepted: 13 December 2017

Published online: 27 December 2017

References

1. Brasil. Instituto Brasileiro de Geografia e Estatística. Dados preliminares do Censo 2012 já revelam mudanças na pirâmide etária brasileira. Rio de Janeiro: IBGE; 2012.

2. Ciolac EG. Exercise training as a preventive tool for age-related disorders: a brief review. Clinics. 2013;68(5):710-7.

3. Ciolac EG, Rodrigues-da-Silva JM. Resistance training as a tool for preventing and treating musculoskeletal disorders. Sports Med. 2016;46(9):1239-48.

4. Peat G, McCartney R, Croft P. Knee pain and osteoarthritis in older adults: a review of community burden and current use of primary health care. Ann Rheum Dis. 2001;60(2):91-7.

5. Altman RD, Hochberg MC, Moskowitz RW, Schnitzer TJ. Recommendations for the medical management of osteoarthritis of the hip and knee: 2000 update. American College of Rheumatology Subcommittee on osteoarthritis guidelines. Arthritis Rheum. 2000;43(9):1905-15.

6. Vincent KR, Vincent HK. Resistance exercise for knee osteoarthritis. PM R. 2012;4(5 Suppl):S45-52. 
7. Ciolac EG, Silva JM, Greve JM. Effects of resistance training in older women with knee osteoarthritis and total knee arthroplasty. Clinics. 2015;70(1):7-13.

8. Fransen M, McConnell S, Bell M. Exercise of osteoarthritis of the hip or knee. Cochrane Database Syst Rev. 2003;3:CD004286.

9. de Rezende MU, Campos GC, Pailo AF, Frucchi R, Pasqualin T, Camargo OP. PARQVE-project arthritis recovering quality of life by means of education short-term outcome in a randomized clinical trial. J Arthritis. 2013;2(2):113.

10. de Rezende MU, Hissadomi MI, Campos GC, Frucchi R, Pailo AF, Pasqualin T, et al. One-year results of an educational program on osteoarthritis: a prospective randomized controlled trial in Brazil. Geriatr Orthop Surg. 2016; 7(2):86-94.

11. Ravaud P, Dougados M. Radiographic assessment in osteoarthritis. J Rheumatol. 1997;24(4):786-91.

12. Altman R, Asch E, Bloch D, Bole G, Borenstein D, Brandt K, Christy W, Cooke TD, Greenwald R, Hochberg M, et al. Development of criteria for the classification and reporting of osteoarthritis: classification of osteoarthritis of the knee. Diagnositic and therapeutic criteria Committee of the American Rheumatism Association. Arthritis Rheum. 1986;29:1039-49.

13. Hoeger WW, Hopkins DR. A comparison of the sit and reach and the modified sit and reach in the measurement of flexibility in women. Res Q Exerc Sport. 1992;63(2):191-5.

14. Montgomery PS, Gardner AW. The clinical utility of a six-minute walk test in peripheral arterial occlusive disease patients. J Am Geriatr Soc. 1998;46(6):706-11.

15. Hinman MR, O'Connell JK, Dorr M, Hardin R, Tumlinson AB, Varner B. Functional predictors of stair-climbing speed in older adults. J Geriatr Phys Ther. 2014;37(1):1-6.

16. Whitney SL, Wrisley DM, Marchetti GF, Gee MA, Redfern MS, Furman JM. Clinical measurement of sit-to-stand performance in people with balance disorders: validity of data for the five-times-sit-to-stand test. Phys Ther. 2005; 85(10):1034-45.

17. Mathias S, Nayak US, Isaacs B. Balance in elderly patients: the "get-up and go" test. Arch Phys Med Rehabil. 1986;67(6):387-9.

18. Pardini R, Matsudo S, Araújo T, Matsudo V, Andrade E, Braggion G, et al. Validação do questionário internacional de nível de atividade física (IPAQ versão 6): estudo piloto em adultos jovens brasileiros. Rev Bras Cien Mov. 2001;9(3):45-51.

19. Borg GAV. Psychophysical bases of perceived exertion. Med Sci Sports Exerc. 1982;14(5):377-81.

20. Zhang W, Nuki G, Moskowitz RW, Abramson S, Altman RD, Arden NK, et al. OARSI recommendations for the management of hip and knee osteoarthritis, part III: changes in evidence following systematic cumulative update of research published through January 2009. Osteoarthr Cartilage. 2010;18:476-99

21. Barlow JH, Turner AP, Wright CC. A randomized controlled study of the arthritis sef-management programme in UK. Health Educ Res. 2000; 15(6):665-80.

22. Ravaud P, Filipo RM, Boutron I, Roy C, Mahmoudi A, Giraudeau B, et al ARTIST (osteoarthritis intervention standardized) study of standardised consultation versus usual care for patients with osteoarthritis of the knee in primary care in France: pragmatic randomised controlled trial. BMJ. 2009; 338:b421.

23. Ravaud P, Giraudeau B, Logeart I, Larguier JS, Rolland D, Treves R, EullerZiegler L, Bannwarth B, Dougados M. Management of osteoarthritis (OA) with an unsupervised home based exercise programme and/or patient administered assessment tools. A cluster randomised controlled trial with a 2x2 factorial design. Ann Rheum Dis. 2004;63(6):703-8.

24. de Rezende MU, de Farias FES, da Silva CAC, Cernigoy CHA, de Camargo OP. Objective functional results in patients with knee osteoarthritis submitted to a 2-day educational programme: a prospective randomised clinical trial. BMJ Open Sport Exerc Med. 2016;2(1):e000200.

25. Rezende MU, Frucchi R, Pailo AF, Campos GC, Pasqualin T, Hissadomi MI. Parqve: project arthritis recovering quality of life through education: twoyear results. Acta Ortop Bras. 2017;25(1):18-24.

26. Ciolac EG, Greve JM. Muscle strength and exercise intensity adaptation to resistance training in older women with knee osteoarthritis and total knee arthroplasty. Clinics. 2011;66(12):2079-84.

27. Richardson JLSA, Sinclair S, Harris J, Letts L, Maclntyre NJ, Wilkins S, BurgosMartinez G, Wishart L, McBay C, Martin Ginis K. Self-management interventions for chronic disease: a systematic scoping review. Clin Rehabil. 2014;28(11):1067-77
28. Blagojevic MJC, Jeffery A, Jordan KP. Risk factors for onset of osteoarthritis of the knee in older adults: a systematic review and meta-analysis. Osteoarthr Cartilage. 2010;18(1):24-33.

29. Rosales $A E$, Brito NL, Frucchi $R$, de Campos GC, Pailo AF, de Rezende MU. Obesity, ostearthritis and clinical treatment. Acta Ortop Bras. 2014; 22(3):136-9.

30. Tilg $H$, Moschen AR. Adipocytokines: mediators linking adipose tissue, inflammation and immunity. Nat Rev Immunol. 2006;6(10):772-83.

31. de Oliveira CM, Sakata RK, Issy AM, Gerola LR, Salomão R. Citokines and pain. Rev Bras Anestesiol. 2011;61(2):255-65.

32. Freitas Lima LC, Braga VA, do Socorro de Franca Silva M, Cruz JC, Sousa Santos SH, de Oliveira Monteiro MM, Balarini CM. Adipokines, diabetes and atherosclerosis: an inflammatory association. Front Physiol. 2015;6:304.

33. Soares MR, Pereira CAC. Teste de caminhada de seis minutos: valores de referência para adultos saudáveis no Brasil. J Bras Pneumol. 2011; 37(5):576-83.

34. Ostir GVMK, Black SA, Goodwin JS. Lower body functioning as a predictor of subsequent disability among older Mexican Americans. J Gerontol A Biol Sci Med Sci. 1998;53(6):M491-5.

35. den Ouden MESM, Arts IE, van der Schouw YT. Association between physical performance characteristics and independence in activities of daily living in middle-aged and elderly men. Geriatr Gerontol Int. 2013; 13(2):274-80

\section{Submit your next manuscript to BioMed Central and we will help you at every step:}

- We accept pre-submission inquiries

- Our selector tool helps you to find the most relevant journal

- We provide round the clock customer support

- Convenient online submission

- Thorough peer review

- Inclusion in PubMed and all major indexing services

- Maximum visibility for your research

Submit your manuscript at www.biomedcentral.com/submit

) BioMed Central 